\title{
The information superhighway and psychiatry
}

\author{
Carl Littlejohns and Martin Briscoe
}

The internet, a milliary crection, is a collection of services shoped by its users, and oflers the rapid transter of vast quantities of informotion. Aheady there b concem that Doveloping World countries may bo len behind by this revolution in information avallablithy. Poychiatitets need to be aware of the type of facility the information in the superishway provides, so that the uectul aspects con be refined and drected. The type of focilities in use now by poychiotitists cround the world is briefly described.

In 1969 the American military set up ARPAnet, a network of computers that would be able to withstand partial destruction. Its design was based on the assumption that control of data flow from a central hub would make a network vulnerable to attack. To overcome this the ARPAnet's designers determined that every computer on the network should be able to communicate with every other. Thus data flow would be re-routed if part of the network was destroyed. The ARPAnet rapidly expanded to encompass other United States government institutions. In the 1980s many universities and businesses developed local networks. These were linked with each other and with the government network. This 'network of networks' was named the Internet. From a thousand or so systems in the mid-1980s, the Internet had grown to an est1mated 30000 networks by 1994 with more than 25 million people having access to it. These linked computers are a repository for databases holding information for businesses and educational centres. Thousands of discussion groups with specialised interests in topics ranging from cross-stitch to molecular biology link like-minded people across the Internet.

\section{Paychiatry resources on the Internet}

Although formal lists of Internet resources exist, and are useful starting points, they quickly go out of date. This article was compiled by using a combination of indexes and some of the computerised searching tools of the Internet to find the types of information on offer for psychiatrists. Exploring the Internet in this way is termed "surfing the "net".

\section{Lbrary facillities}

Most libraries offer on-line telephone or local CDROM literature searching and both are immensely useful tools. However, on-line systems usually have to be searched for (and not by) the person wanting the information. Local facilities are often busy and it can take some time to do a thorough search. Being able to search from home or office, or with a portable computer and mobile phone from anywhere, at any time is one of the advantages of the Internet. Subscription and usage charges are usually levied by the providers of such facilities but usefully the British Medical Association provide free Medline literature searching for their members. This faclity along with their library catalogue can be accessed by a direct call to London, or from any point on the Internet (Elameer, 1993).

CompuServe, the large USA-based electronic message and conferencing system, carries many searchable databases, and now includes a full Internet access in a reduced subscription. Paperchase and Knowledge index hold several databases useful to psychiatrists such as Medline, Index Medicus and a variety of others covering psychology, pharmacology and medical administration. CompuServe access is simple from the UK. Their network is linked to, but not part of, the Internet. The Internet also holds library catalogues, dictionaries and international disease classifications all of which can be searched. The 54000 titles currently recetved by the British Library Document Supply Centre and 170000 journals that have ceased publication can be ordered on-line after searching by title and then, for a charge, sent on by fax. The National Library of Medicine, which holds over 4.5 million books and other audio-visual items, provides a number of on-line services including databases on the neurosciences and psychiatry. The American Academy of Child and Adolescent Psychiatry publish details of their information sheets on such matters as the depressed child, teenage suicide, and child sexual abuse. A wide variety of newspapers can be searched on-line, in many cases including the full text of news items. A number of international medical bulletins are circulated. 'NIBnews' describes Brazilian and 
Latin-American activities in healthcare and medicine. The 'Handicap Digest' is only distributed electronically and consists of articles relating to handicap taken from various news groups and other electronic conferences such as Chronic Pain. Spinal Injury and Rare Conditions.

Various universities use the Internet to inform about their research activities and advertise courses and posts. The Canadian government has produced a 'conversational hypertext' system. This is a search program that can interpret questions typed in plain English. A demonstration version is available over the Internet and will accept questions about AIDS and epilepsy.

\section{File archives}

Collections of psychiatry-oriented files of text, data or software exist, although much more is buried within medical and other file areas. These files can be downloaded and include programmes on symptom ratings, suicide assessment, behaviour modification, computer assisted learning and statistical analysis.

\section{Electronic mail and listservers}

Electronic mail (e-mail) is perhaps the simplest facility offered by the Internet. Flles and messages can be sent from one user to another, usually taking just a few minutes to reach their destination. Unlike fax these messages can be sent for the price of a local phone call and because the information reaches the recipient in electronic form the file can be imported into the readers' own programmes for further manipulation. This is very useful for people engaged in collaborative work, for example the text of this article has travelled some 5000 'electronic' miles between the authors during its development.

A listserver is an automatic mailing list, usually relating to a specific subject. Once a person is registered all subsequent discussion on that subject is then sent to him/her, and any comment or reply is then mailed to the whole group. The fact that the individual group members may never have met each other, and might all read their 'mail' and make their replies at different times (in different time zones) is not at all evident. For people wishing to review what has been said over the past months all the messages are stored in an 'archive' flle. There are hundreds of listservers with a psychological/psychiatric theme.

\section{InterPojch}

Much of the information relating to mental health has been drawn together by Interpsych.
This is an organisation with over 7000 members drawn from disciplines as diverse as anthropology, neuroscience, pharmacology, psychiatry and sociology. It runs a large number of lists or 'scholarly electronic conferences' with a predominantly psychiatric/psychology flavour. The Internet offers the possibility of rapid dissemination of research data, and ease in conducting discussions over disciplinary and geographic boundaries. In order to encourage the use of the Internet in psychiatry Interpsych produces an electronically distributed journal containing general information concerning developments within Interpsych, current events in mental health, mental health resources on the Internet as well as listing physical and electronic conferences and employment opportunities around the world. One of their most ambitious projects is the setting up of a 'Virtual Campus' for mental health. Further details of the InterPsych system are sent to people joining the maillists.

\section{News groups}

The news network, or 'Usenet' is a diverse collection of 24-hours-a-day discussions between large numbers of people. These conversations (or newsgroups) are divided into streams of subjects, and operate a bit like listservers, but with a higher level of activity. Examples of newsgroups include discussions on medicine, AIDS and psychology.

\section{The future}

The rapid growth of Internet will continue. This year will see the UK government providing more on-line information which could include text of ministers' speeches, health policy documents and in time perhaps even league tables for hospitals. Our College could use e-mail to distribute documents rapidly and cheaply to its members and even consider using the Internet to publish fact sheets on illness and treatments for the public. Help lines could be created to provide professionals with rapid advice on treatment and diagnosis. It is anticipated that universities and other bodies will increasingly use the Internet for educational courses up to degree standard and beyond.

\section{How to access the Internet}

There are two ways to access the Internet. The first is to use a university or medical school computer with a direct Internet link. The second is to use a personal computer with a modem to dial into a network over the telephone. The 
cheapest but not necessarily the easiest network to access in this way is the local university but registering could be difficult for those without an academic contract. Alternatively one can subscribe to one of a number of commercial organisations such as CompuServe or Demon. These companies will often have sophisticated software interfaces and offer access to on-line encyclopaedias, software, news and much more. Competition between providers is fierce, and special offers abound.

We moderate an Internet newslist on computers in mental health. To join send the following message 'subscribe computers-in-mental-health' to listserv@netcom.com.

\section{Reference}

ELAMEER, M. S. (1993) Literature search from home. Psychiatric Bulletin, 17, 554-555.

*Carl Littlejohns, Consultant Psychiatrist, Lwyn y Groes Adult Psychiatric Unit, Wrexham Maelor Hospital, Wrexham, Clwyd LL13 7DT, e-mail: csljohns@cix.comulink.co.uk; and Martin Briscoe, Consultant Psychiatrist, Wonford House Hospital, Dryden Road, Wonford, Exeter EX2 5AF; e-mail: M.H.Briscoe@exeter.co.uk

*Correspondence

\title{
The Royal College of Psychiatrists' Journal of Continuing Professional Development
}

\section{Advances in Psychiatric Treatment}

\author{
Editor: Andrew Sims, Director of Continuing Professional Development
}

This innovative new bi-monthly journal has been designed to promote continuing professional development in psychiatry. Each issue will include articles dealing with physical and psychological treatments, one of the specialties, and management topics.

This will be essential reading for every practising mental health professional who needs to be kept informed of current ideas, techniques and developments in psychiatry.

Subscription rate for Volume 1, 1994/5 (8 issues starting September 1994): Europe, including UK $£ 50.00$ USA US\$80.00 Elsewhere $£ 60.00$ Full airmail $£ 6 / \$ 10$ extra

To enter your subscription or to obtain a sample copy of APT, contact:

Publications Subscription Department, Royal Society of Medicine Press Limited, PO Box 9002,London W1M 0ZA, UK. Tel: (+44) 0171290 2927/8; Fax: (+44) 01712902929 